\title{
2009-2013 Yılları Arasında Uzaktan Eğitim Dergilerinde Yayınlanan Makalelerin Yöntemsel Açıdan İncelenmesi ${ }^{*}$
}

Aslıhan BABUR ${ }^{1}$

Barış ÇUKURBAŞI ${ }^{3}$

İsmail TONBULOĞLU ${ }^{5}$
Aydın KİPER ${ }^{2}$

Ebru ALBAYRAK ÖZER ${ }^{4}$

Şirin KÜÇÜK ${ }^{6}$

Eda DEMIRHAN ${ }^{7}$ Özlem CANAN GÜNGÖREN ${ }^{8}$

Mübin KIYICI ${ }^{9} \quad$ Mehmet Barış HORZUM ${ }^{10}$

Öz

$\mathrm{Bu}$ araştırmanın amacı uzaktan eğitimle ilgili 8 dergideki (Internet and Higher Education, American Journal of Distance Education, International Review of Research in Open and Distance Learning-IRRODL, Online Journal of Distance Learning Administration- OJDLA, Open Learning: The Journal of Open, Distance and e-Learning, Turkish Online Journal of Distance Education-TOJDE, European Journal of Open, Distance and E-Learning -EURODL, Distance Education) son beş y1lda yayınlanan makaleleri yöntem kısmı bakımından incelemektir. Araştırma belge incelemesi yöntemi ile gerçekleştirilmiştir. Araştırma kapsamında uzaktan eğitim ile ilgili yayın yapan sekiz derginin son 5 yıl içerisinde yayınladıkları toplam 1233 makale analiz edilmiştir. Çalışmada incelenen makaleler araştırma türü, deseni, örneklem seçimi, örnekleme yöntemi, ölçme aracı ve analiz yöntemi açısından analiz edilmişlerdir. Çalışmadan elde edilen sonuçların uzaktan eğitim alanında gelecek çalışmalara yön vermede belirleyici bir kaynak olarak kullanılabileceği düşünülmektedir. Bu doğrultuda gelecek çalışmaların farklı tarih aralığında, dergi sınırlaması yapılmadan makalelerin incelenmesiyle uzaktan eğitim araştırmalarının gelişimi ve eğilimlerini yansıtmada daha geniş bir tablo çizeceği düşünülebilir.

Anahtar Kelimeler: Uzaktan Eğitim, Belge İncelemesi, Yöntemsel İnceleme.

\footnotetext{
* Bu çalışma 20-22 Mayıs 2014 tarihinde Uluslararası Öğretim Teknolojileri ve Öğretmen Eğitimi Sempozyumunda (2rdInternational Instructional Technologies \& Teacher Education Symposium) sunulan ve tam metin olarak bildiriler kitapçı̆̆ında yer almayan aynı adlı bildirinin genişletilmiş ve geliştirilmiş halidir.

1 Öğr. Gör., Amasya Üniversitesi, Teknik Bilimler MYO, aslihan_babur@yahoo.com

2 Öğr. Gör. Sakarya Üniversitesi, Eğitim Fakültesi, BÖTE, akiper@sakarya.edu.tr

${ }^{3}$ Arş. Gör., Bartın Üniversitesi, Eğitim Fakültesi, BÖTE, bcukurbasi@bartin.edu.tr

${ }^{4}$ Arş. Gör., Sakarya Üniversitesi, Eğitim Fakültesi, BÖTE, ealbayrak@sakarya.edu.tr

${ }^{5}$ Arş. Gör., Yıldız Teknik Üniversitesi, Enformatik Bölümü, ismailt@yildiz.edu.tr

${ }^{6}$ Arş. Gör., Necmettin Erbakan Üniversitesi, Eğitim Bilimleri Enstitüsü, skucuk@konya.edu.tr

7 Yrd. Doç. Dr., Sakarya Üniversitesi, Eğitim Fakültesi, Özel Eğitim Anabilim Dalı, edemirhan@sakarya.edu.tr

${ }^{8}$ Yrd. Doç. Dr. Sakarya Üniversitesi, Eğitim Fakültesi, BÖTE, ocanan@sakarya.edu.tr

${ }^{9}$ Doç. Dr., Sakarya Üniversitesi, Eğitim Fakültesi, BÖTE, mkiyici@sakarya.edu.tr

${ }^{10}$ Doç. Dr., Sakarya Üniversitesi, Eğitim Fakültesi, BÖTE, mhorzum@sakarya.edu.tr
} 


\title{
Examine of Methodological Aspects of Articles in the Journal of Distance Education Year 2009-2013
}

\begin{abstract}
The purpose of the study is to examine articles, published in 8 journals (Internet \& Higher Education, American Journal of Distance Education, International Review of Research in Open and Distance Learning-IRRODL, Online Journal of Distance Learning Administration- OJDLA, Open Learning: The Journal of Open, Distance and e-Learning, Turkish Online Journal of Distance EducationTOJDE, European Journal of Open, Distance and E-Learning -EURODL, Distance Education) in the last 5 years, about distance education with respect to the method. This study was conducted with qualitative document review method. A total of 1233 articles, which was published in 8 journals in the last 5 years about distance education, were analyzed within the scope of this research. Articles examined in the study were analyzed in terms of type of research, design, sample selection, sampling methods, measurement tools and analysis methods. It is thought that the results obtained from this study could be used as a diagnostic resource to guide future studies in the field of distance education. In this direction, it can be thought that with the article investigation, without article restriction and with different date range, a wider trend could be drawn in reflecting distance education development and inclination.
\end{abstract}

Keywords: Distance Education, Document Review Methodological Review.

\section{GİRIŞ}

Uzaktan eğitim; eğitimde eşitlik sağlanmasına, herkesin yaşam boyu eğitim almasına imkân sağlayan, bireysel ve toplumsal amaçların gerçekleştirilmesine katkıda bulunabilen, eğitim teknolojilerinden faydalanarak bireysel öğrenmeyi destekleyen bir disiplindir (Kaya, 2002). 19. yüzyıldan bu yana gelişmekte olan uzaktan eğitim; kuram ve uygulamayı birleştiren bir yapı oluşturarak araştırma ve akademik ilgi alanına dönüşmüştür (Kaya, 2002). Uzaktan eğitim alanında ilerleyebilmek için, şu an nerede bulunduğumuzu anlamak önemlidir (Hauser, 2013).

Uzaktan eğitim literatürü incelendiğinde, 1980'li yıllardan itibaren uzaktan eğitim ile ilgili sınıflandırma şemaları geliştirebilmek amacıyla uzaktan eğitim alanında yapılan araştırmalar üzerinde birçok değerlendirme yapıldığı görülmektedir. Bu değerlendirme sonuçlarına göre uzaktan eğitimde temel araştırma konuları olarak öğrenci desteği, öğretim tasarımı, eğitim teknolojileri vb. kabul görmektedir (Zawacki-Richter, 2009).
Holmberg (1985), "Status and Trends of Distance Education" kitabında uzaktan eğitim disiplininin yapısını tanımlamaya çalışmış ve uzaktan eğitimi felsefe ve uzaktan eğitim teorisi; uzaktan eğitim alan öğrenciler; öğrencilerin ortamları; koşulları ve motivasyonları; ana fikir; öğrenciler ve destekleyici kuruluş (öğretmenler, danışmanlar, yöneticiler, diğer öğrenciler vb.) arasında iletişim ve etkileşim; yönetim ve organizasyon; ekonomi; sistemler (karşılaştırmalı uzaktan eğitim, tipolojiler, değerlendirme vb.) ve uzaktan eğitimin tarihçesi olmak üzere sekiz konuda kategorize etmiştir. Scriven (1991) ise 1989 yılında on yılını tamamlamış olan Distance Education dergisinde yer alan makaleleri incelemiştir. Çalışma sonucunda uzaktan eğitim alanını dokuz kategoriye ayırmıştır. Öğrenen ve özellikleri; temel programlar ve kurslar; telekomünikasyon ve medya; belirli ülkeler ( uygulama ve prosedürleri); teori; kurs tasarımı ve geliştirme; ekonomi ve yönetim; danışmanlık ve öğrenci desteği; öğretmen, personel geliştirme ve kişisel katılım. Ayrıca Panda (1992) incelemiş olduğu 142 çalışmadan kavram, büyüme ve gelişme; müfredat, kurs planlamave geliştirme; öğretme ve 
tasarım; medya ve teknoloji; öğrenen ve öğrenme; kurumsal politika ve yönetimi; ekonomi; değerlendirme ve program değerlendirme ve personel gelişimi olmak üzere dokuz konu belirleyerek uzaktan eğitimi kategorizelendirmiştir.

Sherry (1996) ise incelediği çalışmaları anahtar katılımc1, teknoloji seçimi ve kabulü, tasarım konuları, etkileşim ve aktif öğrenmeyi artırmak için stratejiler, öğrenen özellikleri, öğrenci desteği, işlemsel konular, politika ve yönetim sorunları, eşitlik ve ulaşılabilirlik ve maliyet/fayda denge rollerini yeniden tanımlanması konularına göre ele almıştır. Bunun yanı sıra Rourke ve Szabo (2002) tarafından The Canadian Journal of Distance Education dergisi esas alınarak 1986 - 2001 yılları arasında yayınlanan makaleler içerik analizi ile incelenmiştir. Çalışma sonuçlarına göre, yönetim; değerlendirme; uzaktan eğitimin temeli; öğretim tasarımı; öğretmenin özellikleri; uluslararası bakış açılar1; öğrenen özellikleri; eğilimler; teknoloji ve medya olmak üzere dokuz basamakta sinıflandırılmıştır.

Zawacki-Richter (2009) birbirleriyle ilişkili üç araştırma yürütmüştür. Araştırmalardan ilki 2009 yılında uzaktan eğitimde araştırma alanlarında sinıflandırmak, uzaktan eğitimde en önemli araştırma alanları belirlemek ve uzaktan eğitimde en çok ihmal edilen araştırma alanlarını belirleyebilmek amacıyla yapılmıştır. Delphi tekniği kullanarak yürütülen bu çalışmada üç seviyede on beş alan belirlenmiştir. Bu çalışmalara ek olarak Koble ve Bunker (1997) The American Journal of Distance Education dergisinde 1987-1995 yılları arasinda yayınlanan makaleleri inceleyerek uzaktan eğitim alanını 7 basamakta; Mishra (1997) uzaktan eğitim alanındaki süreli yayınlardan 1991-1996 yılları arasındaki makaleleri inceleyerek 7 basamakta, Berge ve Mrozowski (2001) 1990-1999 yılları arasındaki makaleleri inceleyerek 10 basamakta sınıflandırmışlardır. Çalışmalar göz önüne alındığında uzaktan eğitim araştırma konularında öğrenci desteği, öğretim tasarımı, eğitim teknolojileri, medya ve etkileşim olarak genel bir eğilim olduğu görülmektedir.

Uzaktan eğitim alanında yapılan literatür inceleme araştırmaları uzaktan eğitim ve geleneksel eğitim karşılaştırılması (Hwang, Vu ve Chen, 2012), uzaktan eğitimdeki bariyerler (Chung ve Khor, 2015), öğrenen doyumu (Koper, 2015) gibi çeşitli konulara odaklanmıştır. Bu araştırmaların her biri alanında önemli olmasına rağmen, araştırmaların çoğunda deneysel çalı̧̧maların incelenmesi ile ilgili aynı zayıflık vardır (Hauser, 2013). Bazı araştırmacılar da (Anglin ve Morrison, 2000; Diaz, 2000; Perraton, 2000; Phippse ve Merisotis, 1999; Saba, 2000) uzaktan eğitim literatürünün nicel olarak kalitesini zayıf bulmuşlardır (Bernard, Abrami, Lou ve Borokhovski (2004).

Berge ve Mrozowski (2001)' nin çalışması Hauser (2013)' in eleştirdiği çalışmalardan sadece biridir. Berge ve Mrozowski (2001), The American Journal of Distance Education (USA), Distance Education (Australia), Journal of Distance Education (Canada), Open Learning (UK) dergileri ve tez özetleri arasından 1990 - 1999 yılları arasındaki çalışmaları incelemiştir. Toplamda 1419 çalışma incelenmiş olup, bu çalışmalardan 890' 1 araştırmaya dâhil edilmiştir. İki yıl süren veri toplama sürecinin ardından, çalışmalar Sherry (1996)' nin içerik alanları, araştırma yöntemi ve eğilimler sınıflandırması dikkate alınarak incelenmiştir. Sınıflamalardan araştırma yöntemi bölümünde çalışmaların 666'sinı betimsel, 112' sini durum, 59'unu korelasyon ve 53'ünü de deneysel çalışmalar oluşturmaktadır.

Bernard vd. (2004) yapmış oldukları çalışmada 1985-2002 yılları arasındaki 232 uzaktan eğitim çalışmasını inceleyerek meta analiz çalışması yapmıştır. Araştırma sonucunda uzaktan eğitim alanında kullanılan nicel yöntemlerin düşük kalitede olduğu ayrıca deneysel kontrol, katılımcların rasgele seçilmesi, katılımcıların uygun koşullarda değerlendirilmesi, geçerlilik ve güvenirliği sağlanmış değerlendirmelerin yapılması, öğrenci ve öğretmenlerin tutumları (Anglin ve Morrison, 2000; Perraton, 2000) gibi 
araştırma uygulamaları hakkındaki bilgilerde eksiklik olduğu bulunmuştur.

Zawacki-Richter (2009) sinıflandırma yaptığ1 araştırmasının ardından Bäcker ve Vogt (2009) ile birlikte, alandaki boşlukları ve öncelikli alanları belirleyebilmek amaciyla 2000 - 2008 yılları arasında yer alan makaleleri araştırma alanı, yöntem ve yazar sayısı açısından incelemiştir. Uzaktan eğitim alanında tanınmış olmaları nedeniyle Open Learning (OL), Distance Education (DE), the American Journal of Distance Education (AJDE), the Journal of Distance Education (JDE) ve the International Review of Research in Open and Distance Learning (IRRODL) dergileri seçilmiştir. Bu dergiler arasından 695 makale çalışmaya dâhil edilmiştir. 2000-2008 yılları arasında öğrenme topluluklarında etkileşim ve iletişim (122) alanı üzerinde; nicel (202) ve çoğunlukla tek yazarlı çalışmalar yapılmıştır.

2009 yılında yaptığı makale incelemesinin ardından Zawacki-Richter ve vonPrümmer (2010), araştırmacılar arasındaki cinsiyet ve iş birliği değişkenlerinin araştırma yöntemlerine, araştırma konularına ve araştırma verimliliğine etkisini araştırmışlardır. Araştırma sonucuna göre, kadın araştırmacılar erkek araştırmacılara göre daha farklı konular üzerinde çalışmışlardır. Kadın araştırmacılar öğrenen özellikleri, öğrenme topluluklarında öğrenen desteği veya etkileşim ve öğrenen iletişimi gibi araştırma alanlarının içinde daha fazla yer alırken, erkek araştırmacılar teknoloji ve yönetim konuları üzerinde yoğunlaşmıştır. Yöntem açısından incelendiğinde kadın araştırmacıların araştırmalarında nicel ya da çeşitleme yöntemini sıklıkla kullandığı görülmektedir. Araştırmanın son bulgusu ise, kullanılan yöntemin işbirliğini etkilemesinden dolayı nicel yöntem kullanılan araştırmalardaki işbirliğinin, nitel yöntem kullanılan araştırmalardakine oranla daha fazla görüldüğüdür.

Lee, Driscoll ve Nelson (2010), makalelerinde1997-2002 yılları arasında The American Journal of Distance Education (AJDE), the Journal of Distance Education (JDE), Distance
Education (DE) ve Open Learning: The Journal of Open, Distance and e-Learning (OL) dergilerinde yayınlanan 383 makaleyi araştırma konuları, kullanılan yöntemler ve atıf eğilimlerine göre incelemişlerdir. Araştırma konuları Sherry (1996)' nin sinıflandırması temel alınarak altı basamakta sınıflandırılmıştır. Araştırma kapsamında incelenen 383 makaleden 138' inde (\%36) nitel yöntemlerden durum çalışması kullanılmıştır. İncelenen dört dergide 105 atıfla en fazla atıf alan yazarın Moore (1997) olduğu belirtilmiştir. Ayrıca Lee, Driscoll ve Nelson (2010) uzaktan eğitim araştırmalarında ilerleyebilmek için yeni araştırma yöntem ve paradigmalarına ihtiyaç duyulduğuna değinmişlerdir.

Horzum, Özkaya, Demirci ve Alpaslan (2013) tarafından 2005-2011 yılları arasında yayınlanan Türkçe uzaktan eğitim makaleleri incelenmiştir. Araştırma kapsamında 14 dergide yer alan Türkçe uzaktan eğitim makalelerinden oluşan 35 makalelik bir liste oluşturulmuştur. Oluşturulan liste temel alınarak her makale temel başlıklar halinde incelenmiştir. Bu incelemeler sırasında araştırmacılar tarafından hazırlanan makale inceleme formu kullanılmıştır. Araştırmada dergilerde yer alan makalelerin dilinin Türkçe olması, 2005-2011 yılları arasında basılmış olması ve incelemeye uygun niteliklere sahip olma durumu bakımından sinırlandırılmıştır. Bu çalışmalarda 19'unda nicel, 12 'sinde literatür, $4^{\prime}$ ünde ise nitel paradigma tercih edilmiştir. Çalışmalarda $7^{\prime}$ si tarama, 7'si deneysel, 5'i ölçme aracı geliştirme, 2'si olgu bilim, 2'si durum çalışmasıdır. Araştırma bulgularına göre Türkçe yazılmış makalelerin ağırlıklı olarak nicel paradigmaya dayalı olarak yapıldığı görülmektedir.

Hauser (2013), The American Journal of Distance Education (USA), Distance Education (Australia), The Journal of Distance Education (Canada) ve Open Learning (UK) dergilerinde yer alan 382 makaleyi araştırmasına dâhil etmiştir. Makaleler İngilizce dilinde, nicel veya nitel veri içeren ve 2005-2012 yılları arasında yayınlanmış olma kriterlerine göre belirlenmiştir. Araş- 
tırma sonucuna göre 189 (\%49) makalede nitel araştırma yöntemi kullanılmıştır.

2009-2013 yılları arasında uzaktan eğitim eğilimlerini belirlemek amacıyla içerik analizi çalışması yürütülmüştür (Bozkurt vd., 2015). American Journal of Distance Education(AJDE), Distance Education (DE), European Journal of Open Distance, e- Learning (EURODL), Journal of Distance Education (JDE), Journal of Online Learning and Technology (JOLT), Open Learning: The Journal of Open, Distanceand e-Learning (OL) ve The International Review of Research in Open and Distributed Learning (IRRODL) dergilerinden 1225 makale belirlenerek, kriterlere uygun 861 makale araştırmaya dâhil edilmiştir. Sonuçlar betimsel analiz (frekanslar) ve sosyal ağ analizi kullanılarak yorumlanmış ve çeşitli kategorilerde incelenmiştir: araştırma alanları, kuramsal ve kavramsal çerçeveler, değişkenler, yöntemler, modeller, stratejiler, katılımcilar, veri toplama ve analiz yöntemleri. Ayrıca çalışma en sık kullanılan anahtar kelimeleri, en çok atıf alan yazar ve çalışmaları içermektedir.

Uzaktan eğitimle ilgili çalışmalar incelendiğinde ülkemizde özellikle kullanılan yöntemlerle ilgili sınırlı sayıda çalışma yapıldığı, yurt d1şında yapılan çalışmaların daha çok ve gelişmiş olduğu görülmektedir. Yurt dışında yapılan ve uzaktan eğitim araştırmalarını inceleyen bu makalelerde ön plana çıkan bulgulardan ilki çalışmaların betimsel ağırlıklı olduğu, betimsel olmayan çalışmaların ise yöntemsel olarak problemli olduğudur (Anglin ve Morrison, 2000).

$\mathrm{Bu}$ araştırmanın amacı uzaktan eğitimle ilgili 8 dergideki 2009 - 2013 yılları arasında yayınlanan makaleleri yöntem kısmı bakımından incelemektir. Araştırmanın amacına ulaşabilmesi için "Uzaktan eğitim araştırmalarında kullanılan araştırma yöntemleri ve yönteme yönelik kullanılan modeller nelerdir? Araştırmalardaki örneklem grubu kimlerdir ve kaç kişiyle çalışmalar yürütülmüştür? Veri toplama aracı olarak neler kullanılmıştır? Araştırmalarda kulla- nılan istatistikler nelerdir?" sorularına cevap aranmıştır.

\section{YÖNTEM}

Araştırma belge incelemesi yöntemi ile gerçekleştirilmiştir. Belge incelemesi, görüşme ya da gözlem yapmanın oldukça zor olduğu durumlarda tek başına bir araştırma yöntemi olarak kullanilabilmektedir. Belge incelemesinde amaç, araştırılan olay ya da olgular hakkında yazılı bilgi içeren dokümanların ayrıntılı biçimde analiz edilmesidir (Yıldırım ve Şimşek, 2008. Bu çalışmada da uzaktan eğitim dergilerinde son beş yılda yazılan makalelerin yöntemsel açıdan incelenmesi amaçlandığından bu yöntem tercih edilmiştir.

\subsection{Dergi ve Makalelerin Seçimi}

Araştırma kapsamında uzaktan eğitim ile ilgili yayın yapan sekiz derginin (Internet \& Higher Education, American Journal of Distance Education, International Review of Research in Open and Distance Learning-IRRODL, Online Journal of Distance Learning AdministrationOJDLA, Open Learning: The Journal of Open, Distance and e-Learning, Turkish Online Journal of Distance Education-TOJDE, European Journal of Open, Distanceand E-Learning EURODL, Distance Education) son 5 yıl içerisinde yayınladıkları toplam 1315 makalenin incelenmesi ile oluşturulmuş bir belge incelemesi çalışmasıdır. Bu makalelerden 32 tanesi kitap incelemesi, 43 tanesi ise editörden kısmı olduğu ve 7 tanesi özel sayıya ait giriş yazısı içerdiği için araştırmanın kapsamından çıkarılmıştır. Sonuçta erişilen 1233 makale analiz edilmiştir. Çalışmada incelenen makaleler araştırma türü, deseni, örneklem seçimi, örnekleme yöntemi, ölçme aracı ve analiz yöntemi açısından analiz edilmişlerdir.

\subsection{Veri Toplama Aracı}

Araştırmada veri toplama aracı olarak araştırmacılar tarafından araştırma kapsamında geliştirilen uzaktan eğitim makalelerinde yöntemsel eğilimlerin incelenmesi formu kullanılmıştır. Form geliştirilirken alanda yer alan belge ince- 
leme çalışmaları (Berge ve Mrozowski, 2001; Hauser, 2013; Horzum, Özkaya, Demirci ve Alpaslan, 2013; Lee, Driscoll ve Nelson, 2010; Yıldırım ve Şimşek vd., 2008; Zawacki-Richter, 2009; Zawacki-Richter, Bäcker ve Vogt, 2009) incelenerek bu çalışmalardan yöntemle ilgili incelenen maddeler çıkarılmış ve Fraenkel ve Wallen'ın (2006) araştırma yöntemleri kitabında yer alan boyutlar dikkate alınarak formda doldurulacak maddeler oluşturulmuştur. Formda dergi adı, yayın yılı, temel alınan yöntem, desen, evren ve örneklem, veri toplama araçları, verilerin toplanması ve analizi ile ilgili maddeler yer almıştır. Oluşturulan formla ilgili araştırma yöntemleri ve uzaktan eğitim alanında ders veren 3 alan uzmanından uzman görüşü alınarak forma son hali verilmiştir.

\subsection{Verilerin Toplanması ve Analizi}

Araştırma kapsamında verileri oluşturulacak makaleler araştırmacılar tarafından ilgili dergilerin web sitelerine girilerek yıl, sayı ve cilde göre tek tek indirilerek toplanmıştır. Toplama işleminden sonra makaleler tasnif edilmiş ve seçilen 10 makale tüm araştırmacılar tarafından incelenerek önceden hazırlanmış ortak platformda, formdaki maddelere yansıyacak biçimde doldurulmuştur. Form maddesi ile ilgili emin olunamayan durumlarda uzman görüşü ile sınıflandırılmıştır. Çalışmalar, araştırmacılar arasında paylaşılmıştır. Online ortamda oluşturulan platformda veri girişleri gerçekleştirilmiştir. Girilen verilerden rasgele seçimler yapıla- rak veriler tekrar kontrol edilmiştir. Sınıflandırmanın sonunda oluşan veriler betimsel istatistikî yöntemler olan yüzde ve frekans kullanılarak analiz edilmiştir. Bazı veriler için karşılaştırmalı yüzde ve frekans sunulması yoluna gidilmiştir.

\section{BULGULAR}

\subsection{Yıllara Göre Makale Sayıları}

Uzaktan eğitim çalışmaları incelendiğinde Berge ve Mrozowski (2001) çalışmalarında 1990-1999 ve Zawacki-Richter, Bäcker ve Vogt (2009) 2000-2008 yılları arasında yayınlanan makaleleri incelemişlerdir. Bu nedenle araştırma kapsamına 2009-2013 yılları arasında yayınlanan makaleler ele alınmıştır. Araştırma kapsamında incelenen makalelerin yıllara göre dağılımı incelendiğinde en çok 2013 yılında toplam 315 makaleyle karşılaşılmaktadır. Bunun yanında sirasıyla 2009 yılında 223, 2010 yılında 209, 2011 yılında 236 ve 2012 yılında 250 makale olduğu görülmüştür. Şekil1' de yıllara göre makale sayılarında artış olduğu ve en çok makalenin 2013 yılında olduğu görülmektedir. Uzaktan eğitim dergilerindeki makalelerde son yıllarda artış olduğu ve her geçen yıl artacağını ortaya koymaktadır. Araştırmalardaki artışın uzaktan eğitim çalışmalarının öneminin her geçen gün artmasına bağlanabileceğidüşünülmektedir.

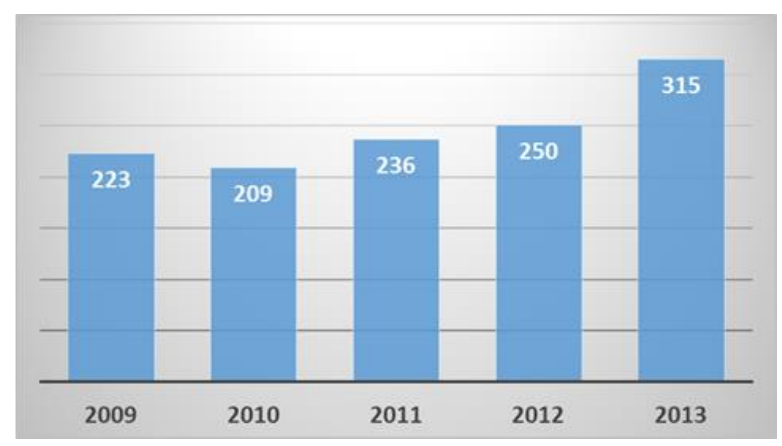

Şekil 1. Yıllara göre yayınlanmış makale sayıları 


\subsection{Dergilere Göre Makale Sayıları}

Araştırma kapsamında incelenen makalelerin dergilere göre dağılımı incelendiğinde en çok makalenin TOJDE dergisinde olduğu bulunmuştur. TOJDE dergisinde toplam 325, IR-
RODL 254, Internet \& Higher Education 162, ODJLA 126, Distance Education 116, Open Learning 90, EURODL 85 ve AJDE 75 makale yayınlandığı bulunmuştur (Şekil 2).

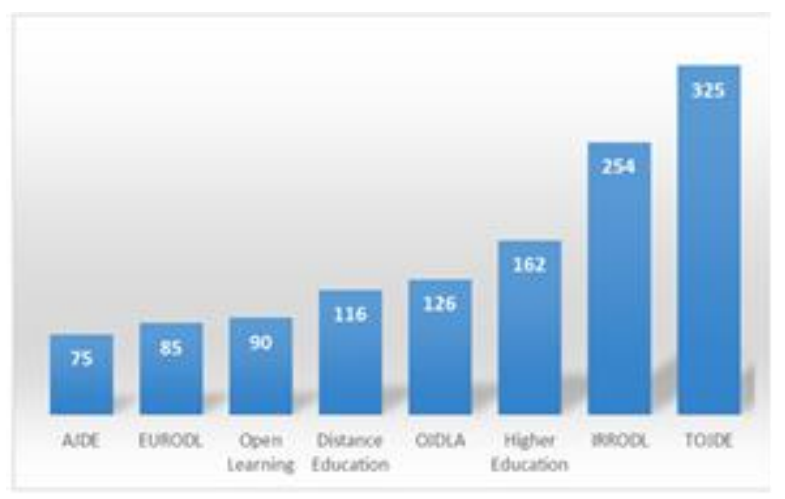

Şekil 2. Dergilere göre yayınlanmış makale sayıları

Sirasıyla 2009, 2010, 2011, 2012 ve 2013 yıllarına göre dergilerdeki makale sayılarına bakıldığında TOJDE dergisinde 54, 54, 54, 59 ve 104; IRRODL dergisinde55, 20, 51, 50 ve 78; Internet \&Higher Education dergisinde22, 45, 31, 35 ve 29; ODJLA dergisinde 24, 29, 27, 20 ve 26; Distance Education dergisinde 19, 19, 26, 26 ve 26; Open Learning dergisinde 23, 19, 20, 19 ve 9; EURODL dergisinde 15, 12, 11, 24 ve 23 ve AJDE dergisinde ise $11,11,16,17$ ve $20^{\prime}$ dir.
Dergilerdeki yayınlanan makale sayıları birbirlerinden oldukça farklı sayıda olduğu görülmektedir. Dergilerin bu yıllar arasinda yılda yayınladıkları toplam cilt sayılarına bakıld1ğında TOJDE dergisi yılda toplam 4, Internet \&Highe rEducation 4; ODJLA 3, Distance Education 3, Open Learning 3, EURODL 2 ve AJDE 4 cilt yayınlandığı bulunmuştur. Bunun yanında IRRODL dergisi yıllara göre sirasıyla 6, 3, 7, 5,5 cilt sayı yayınlanmıştır.

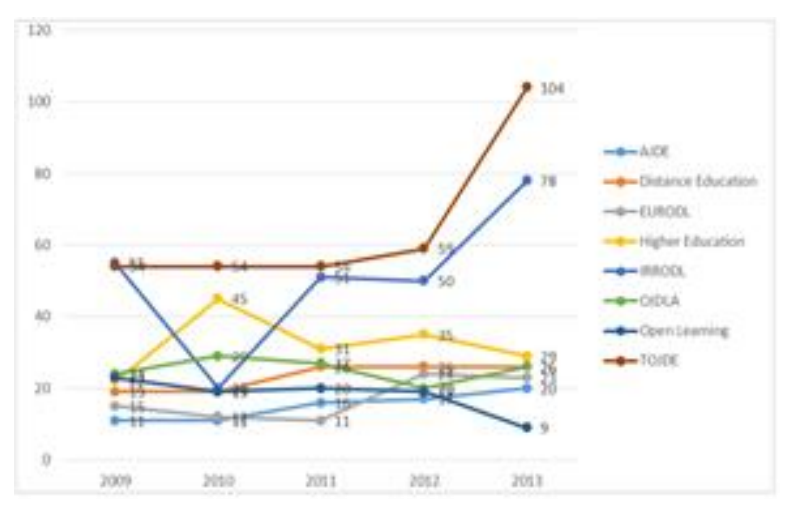

Şekil 3. Yıllara göre dergilerde yayınlanmış makale sayılar

Dergilerin yayın sayılarının birbirinden farklı olması ve yıllara göre düzenli bir sayıda olmamasının nedeni olarak dergilerin yayın politikaları, derginin kendi içerinde koyduğu sınırlamalar, fazla makale gelmemesi, kaliteli yayın- lanabilecek yeterli makale olmaması ya da hedef kitlelerine göre farklı sayıda makale yayınlaması olabilir.

\subsection{Temel Alınan Yöntemler}


İncelenen makalelerin temel aldığı yöntemler incelendiğinde uzaktan eğitimle ilgili dergilerdeki yazılmış makalelerin ağırlıklı olarak nitel paradigmaya dayalı olarak yapıldığı görülmektedir (Şekil 4).

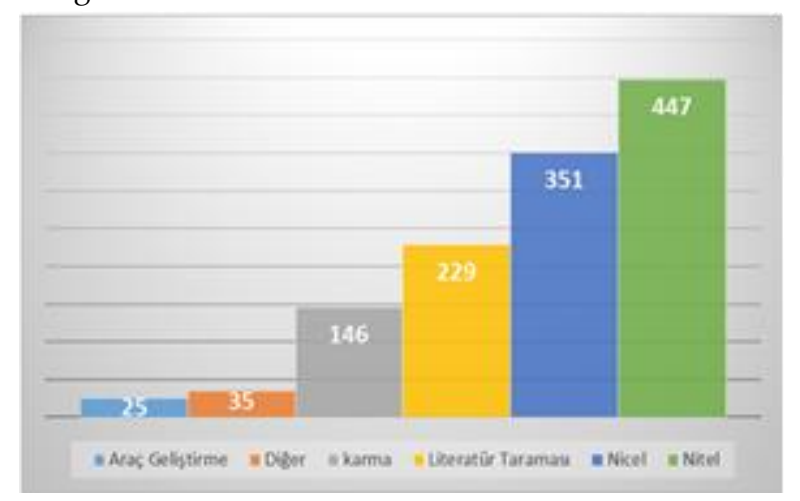

Şekil 4. Yöntemlere göre dergilerde yayınlanan makaleler

Bu makalelerden 447 nitel çalışma, 351 nicel paradigmaya göre yürütülmüş çalışma, 229 literatür taraması makalesi 146 çalışmada hem nicel hem nitel paradigmanın desenlerinin kullanıldığı karma paradigma tercih edilmiş, 25 çalışma araç geliştirme çalışması iken 35 çalışma ise diğer (uygulama tasarlama, desen belirtilmemiş) olarak kodlanmıştır. Bu bulgular 1şığında uzaktan eğitimle ilgili dergilerdeki yazılmış makalelerde daha çok nitel paradigma yöntemlerinin kullanıldığı görülmektedir. Bunun yanında nicel paradigmanın da ağırlıklı olarak kullandığı görülürken, araç geliştirme çalışmalarının ve karma paradigmanın çok fazla ele alınmadığı görülmektedir.

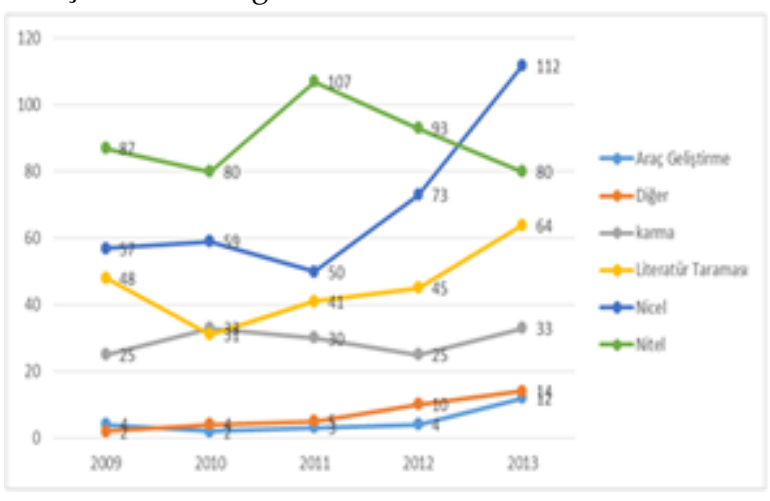

Şekil 5. Yıllara göre dergilerde yayınlanmış makalelerde tercih edilen yöntem sayıları

Ylllara göre uzaktan eğitim dergilerindeki makalelerde tercih edilen yöntemler incelendiğinde araç geliştirme çalışmalarının yıllara göre sirasiyla 4, 2, 3, 4 ve 12 makale olduğu ve bu yönüyle 2013 yılında araç geliştirme çalışmalarında çok ciddi bir artış olduğu görülmektedir (Şekil 5). Karma paradigmanın tercih edildiği araştırmalar incelendiğinde yıllara göre makale sayıları sırasıyla $25,33,30,25$ ve 33 olduğu ve bu yönüyle karma paradigmanın 2009-2013 yılları arasında düzenli bir rakam aralığında yayınlanan yöntem olduğu ifade edilebilir. Literatür taraması makalelerin yıllara göre sayılarındaki değişim incelendiğinde makale sayılarının sirasıyla 48, 31, 41, 45ve 64 tane olduğu ve bu rakamların son yıllarda uzaktan eğitim dergilerindeki makalelerde literatür taramasının artan bir şekilde tercih edildiğini ortaya koymuştur. Nicel yöntemin kullanıldığı çalışmaların yıllara göre sayıları sırasıyla 57, 59, 50, 73 ve 112 olarak belirlenmiştir. Bu rakamlar nicel yöntemin tercih edildiği çalışmaların 2011 
yılında ciddi şekilde azaldığını ancak 2011'den sonra artışa geçip 2013'te diğer yılların nerdeyse iki katına ulaştığını göstermektedir. Nitel yöntemin kullanıldığı çalışmaların yıllara göre sayıları sirasıyla $87,80,107,93$ ve 80 olarak belirlenmiştir. $\mathrm{Bu}$ rakamlar nitel yöntemin tercih edildiği çalışmaların 2011 yılında ciddi şekilde arttığını ancak 2011'den sonra azalma meydana gelip 2013'te diğer yılların en düşük seviyesine geldiğini göstermektedir. Tüm bu bulgular uzaktan eğitim dergilerindeki makalelerde 2011 yılına kadar artan biçimde nitel yöntemler tercih edilirken 2013 yılına gelindiğinde nitel yöntemi tercih eden makalelerin azaldığı, nicel yöntemi, literatür taramasını ve araç geliştirmeyi tercih eden araştırmaların arttığını göstermektedir. Artış gösteren yöntemler içinde nicel paradigma daha yüksek rakamlara sahiptir.

AJDE dergisinde yayınlanan makalelerin yöntem tercihleri incelendiğinde karma paradigma 12, literatür taraması 18, nitel 19 ve nicel paradigma 26 çalışmada kullanılmıştır. AJDE dergisindeki yöntem tercihleri incelendiğinde nicel paradigmanın daha fazla tercih edildiği görülürken diğer yöntemlerin de benzer sayılarda tercih edildiği ve kullanıldığı görülmektedir. EURODL dergisinde yayınlanan makalelerin yöntem tercihleri incelendiğinde karma paradigma 11, literatür taraması 24, nitel 20 ve nicel paradigma 27 çalışmada kullanılmıştır. EURODL dergisindeki yöntem tercihleri incelendiğinde nicel paradigmanın daha fazla tercih edildiği görülürken nitel paradigma ve literatür taraması da yöntemler olarak nicel paradigmayla benzer sayılarda tercih edildiği ve kullanıldığı görülmektedir. Bu dergide karma paradigma en az tercih edilen yöntemken 3 makale ise yöntemsel açıdan diğer olarak sınıflandırılmiştır.

Open Learning dergisinde yayınlanan makalelerin yöntem tercihleri sayılarına göre incelen- diğinde karma paradigma 5, literatür taraması 33, nitel 32 ve nicel paradigma 9 çalışmada kullanılmıştır. Open Learning dergisindeki yöntem tercihlerine göre incelendiğinde literatür taraması ve nitel paradigmanın daha fazla tercih edildiği görülmektedir. Bu dergide karma ve nicel paradigma en az tercih edilen yöntemken 1 makale ise yöntemsel açıdan diğer olarak sınıflandırılmıştır. Distance Education dergisinde yayınlanan makalelerin yöntem tercihlerinin sayılarına göre incelendiğinde araç geliştirme 3, karma paradigma 16, literatür taraması 8, nitel 58 ve nicel paradigma 16 çalışmada kullanılmıştır. Distance Education dergisindeki yöntem tercihlerine göre incelendiğinde nitel paradigmanın daha fazla tercih edildiği görülmektedir. Bu dergide literatür taraması, karma ve nicel paradigma az tercih edilen yöntemlerken 3 makalede araç geliştirme yöntem olarak tercih edilmiştir. Ayrıca dergide 16 makale ise yöntemsel açıdan diğer olarak sınıflandırılmıştır.

OJDLA dergisinde yayınlanan makalelerin yöntem tercihlerinin sayılarına göre incelendiğinde nicel paradigma 54, literatür taraması 39, nitel 21, araç geliştirme 4 ve karma paradigma 3 , ve çalışmada kullanılmıştır. OJDLA dergisindeki yöntem tercihlerine göre incelendiğinde nicel paradigmanın daha fazla tercih edildiği görülmektedir. Literatür taraması ise ikinci en fazla tercih edilen yöntem türüdür. Bu dergide karma ve nitel paradigma az tercih edilen yöntemken 4 makalede araç geliştirme yöntem olarak tercih edilmiştir. Ayrıca dergide 5 makale ise yöntemsel açıdan diğer olarak sınıflandırılmıştır. Internet \& Higher Education dergisinde yayınlanan makalelerin yöntem tercihlerinin sayılarına göre incelendiğinde nicel paradigma 62 , nitel paradigma 47 , karma paradigma 33, literatür taraması 16 ve araç geliştirme 4 çalışmada kullanılmıştır. Internet \& Higher Education dergisindeki yöntem tercihlerine göre incelendiğinde nicel paradig- 
manın daha fazla tercih edildiği, nitel paradigmanın ikinci sırada ve karma paradigmanın üçüncü sırada ve fazlaca tercih edildiği görülmektedir. Bu dergide literatür taraması az tercih edilen yöntemken 4 makalede araç geliştirme yöntem olarak tercih edilmiştir.

IRRODL dergisinde yayınlanan makalelerin yöntem tercihlerinin sayıları nitel paradigma 88, nicel paradigma 61, literatür taraması 51, karma paradigma 41 ve araç geliştirme 8 çalışmada kullanılmıştır. IRRODL dergisindeki yöntem tercihlerine bakıldığında nitel paradigmanın daha fazla tercih edildiği, nicel paradigmanın ikinci sırada, literatür taramasının üçüncü ve karma paradigmanın dördüncü sırada yer aldığı ve bu yöntemlerin fazlaca tercih edildiği görülmektedir. Bu dergide 8 makalede araç geliştirme yöntem olarak tercih edilmiştir. Ayrıca dergide 5 makale ise yöntemsel açıdan diğer olarak sınıflandırılmıştır. TOJDE dergisinde yayınlanan makalelerin yöntem tercihlerinin sayılarına göre incelendiğinde nitel paradigma 162, nicel paradigma 88, literatür taraması 40, karma paradigma 25 ve araç geliştirme 6 ve çalışmada kullanılmıştır. TOJDE dergisindeki yöntem tercihlerine bakıldığında nitel paradigmanın daha fazla tercih edildiği, bu tercihte çok fazla fark olduğu görülmektedir. Dergide nicel paradigmanın ikinci sırada, literatür taramasının üçüncü ve karma paradigmanın dördüncü sırada yer aldığı ve bu yöntemlerin arasında yaklaşık yarı yarıya fark olduğu bulunmaktadır. Bu dergide 6 makalede araç geliştirme yöntem olarak tercih edilmiştir. Ayrıca dergide 6 makale ise yöntemsel açıdan diğer olarak sınıflandırılmıştır.
Dergilere göre yöntem tercihleri incelemesine göre genel olarak incelendiğinde TOJDE, IRRODL, Distance Education dergileri nitel paradigmanın daha fazla tercih edildiği dergiler olurken AJDE, Internet \& Higher Education, OJDLA dergileri ise nicel paradigmanin daha fazla tercih edildiği dergiler olarak karşımıza çıkmıştır. Bunun yanında Open Learning literatür taraması ve nitel paradigma açısından, EURODL ile literatür taraması, nicel ve nitel paradigma benzer sayılarda tercih edildiği görülmektedir.

\subsection{Araştırma Modelleri}

Makalelerde kullanılan araştırma modellerinin dağılımı incelendiğinde nicel paradigmanın modellerinden tarama modeli 376 makalede, deneysel model 77 makalede, korelasyonel desen 34 makalede, nedensel karşılaştırma 20 makalede ve betimsel desen ise 9 makalede tercih edilmiştir. Nitel paradigmanın modellerinden örnek olay 390 makalede, eylem araştırması 65 makalede, fenemenoloji 33 makalede, tarihsel desen 25 makalede, gömülü teori (grounded theory) 15 makalede, üçleme 4 makalede, etnografya 3 makalede ve kültür analizi 1 makalede tercih edilmiştir. Bunların yanı sıra 229 makalede literatür taraması, 48 makalede meta ve doküman analizi, 25 makalede araç ya da uygulama geliştirme ve 35 makale ise diğer olarak sınıflanmıştır. Uzaktan eğitim dergilerindeki makalelerin desen tercihleri ele alındığında nicel paradigmada tarama, nitel paradigmada ise örnek olay desenlerinin açık ara ön plana çıktığı görülmüştür. Çalışmalarda karma paradigmanın modelleri de nitel ve nicel paradigmanın altında ele alınmıştır. 


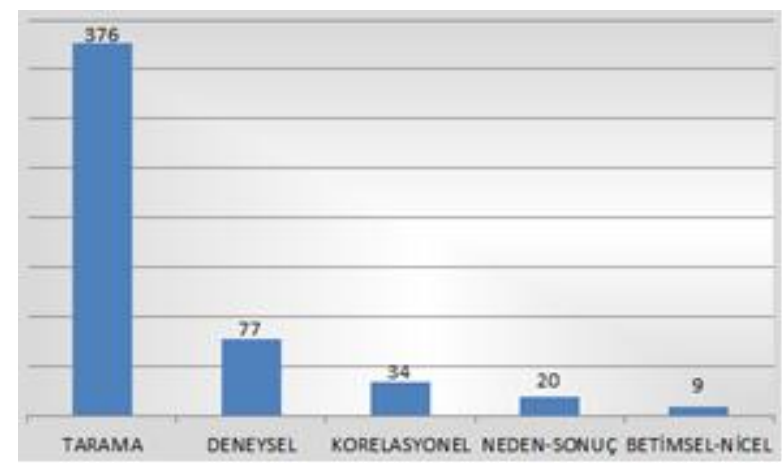

Şekil 6. Nicel yöntemde tercih edilen model sayıları

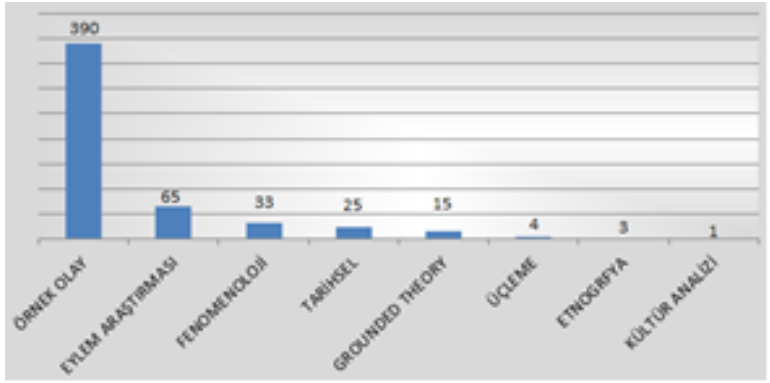

Şekil 7. Nitel yöntemde tercih edilen model sayıları

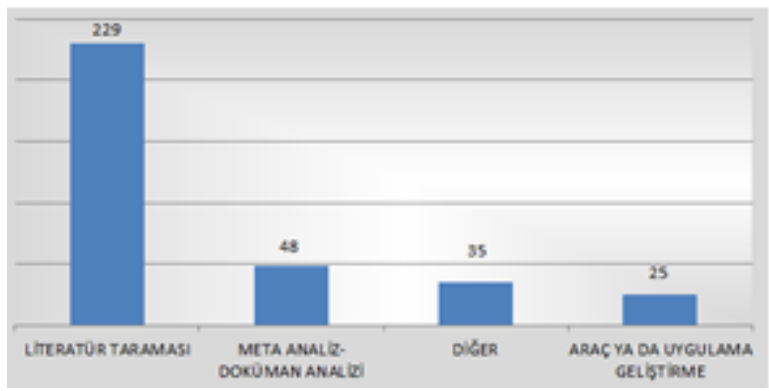

Şekil 8. Diğer yöntemlerde tercih edilen model sayıları

\section{5 Çalışma Grubu/Örneklem/Evren}

İncelenen makalelerde nitel çalışmalarda bulunduğundan kitle, evren, çalışma grubu ve örneklem olarak ele alınmıştır. Çalışmalardan bir bölümü literatür taraması ve araç geliştirme olduğundan bu çalışmalarda örneklem ya da çalışma grubu bulunmamaktadır. İnceleme bunların dışındaki çalışmalarla gerçekleştirilmiştir. Çalışma ya da örneklem grupları incelendiğinde makalelerin 571'i öğrencilerle 397'si ise yetişkinler, öğretmenler ya da diğer katılım- cılarla gerçekleşmiştir. Öğrencilerle yapılan çalışmalardan 12 tanesi ise ilköğretim, 27'si orta öğretim, 435'i lisans, 97'si lisansüstü öğrencileri ile gerçekleştirilmiştir. Bu bulgular, çalışmaların lisans düzeyinde öğrencilerle daha ağırlıklı olduğunu göstermektedir. Bunun yanında lisans öğrencilerinin dişında kalan diğer öğrenciler, öğretmenler ve öğretim elemanları ile ilgili çalışmalara ihtiyaç olduğu ortaya çıkmaktadir. 


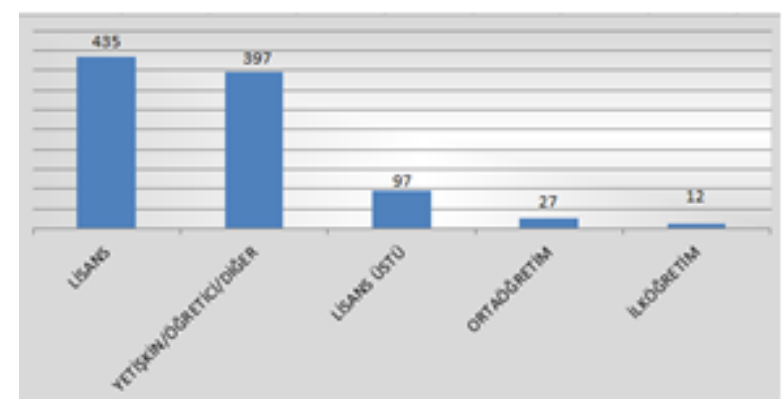

Şekil 9. Çalışma Grubu/Örneklem/Evren katılımcılarının sayıları

Ayrıca katılımcıların ortalama sayılarına bakıldığında ilköğretim öğrencileriyle yapılan çalışmalarda ortalama 151 katılımcıyla, ortaöğretimde 382 katılımcıyla, lisans öğrencileriyle yapılan çalışmalarda ortalama 1278 katılımcı, lisansüstü öğrencileriyle yapılan çalışmalarda ortalama 82 katılımcıyla, yetişkin/öğretmen/ diğer bireylerle yapılan çalışmalarda ortalama 192 katılımcı ile çalışmalar yürütülmüştür.
Araştırmada örneklem alınan çalışmalarda hangi örnekleme yönteminin tercih edildiği incelendiğinde 216 makalede amaçli, 148 makalede basit rasgele, 48 makalede uygun, 6 makalede tabakalı, 3 makalede kartopu ve 1 makalede küme örnekleme yöntemlerinin tercih edildiği bulunmuştur. Bunun yanında 8 makalede ise evrenin tamamına erişilmesi tercih edilmiştir.

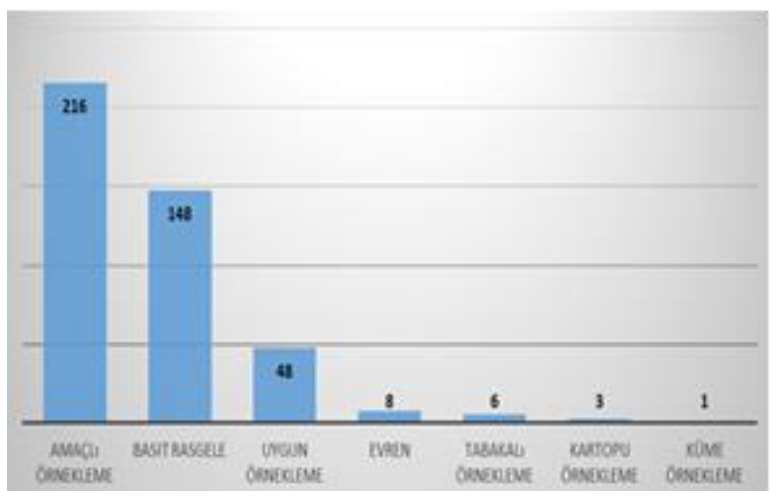

Şekil 10. Tercih edilen örnekleme yöntemlerinin sayıları

\subsection{Veri Toplama Araçları}

Araştırma kapsamındaki makalelerde kullanılan veri toplama araçları incelendiğinde 314 çalışmada anket, 269 çalışmada görüşme formu ya da kayıtları, 224 çalışmada ölçek, 206 çalışmada çevrimiçi ders doküman, makale ve dergileri, 79 çalışmada çevrimiçi gönderi, tweet, sohbet ve forumlardaki mesajlar, 39 çevrimiçi giriş, kaynak, ödev, görev ve etkinlik kayıtları, 32 çalışmada gözlem formu, 31 çalışmada başarı testleri ve genel başarı puanları, 26 çalışmada sosyal medya, wiki ve günlük kayıtları, 17 çalışmada ise portfolyo, kontrol listesi, öğrenci raporları ve rubrikler veri toplama aracı olarak kullanılmıştır. 51 çalışmada ise veri toplama aracı sınıflanamamıs ya da raporlanmamıştır.

\subsection{Kullanılan Veri Analizi Teknikleri}

Makalelerde kullanılan analiz teknikleri ele alındığında 573 makalede nicel ve nitel betimsel analizlerin yapıldığ görülmüştür. Bunun yanında makalelerde nicel parametrik analiz tekniklerinden T-testi 98 makalede, varyans analizi (AN[C]OVA) 75 makalede, çoklu varyans analizi (MAN[C]OVA) 10 makalede, faktör analizi ve güvenirlik 84 makalede, korelasyon 79 makalede, regresyon 58 makalede, diskriminant veya kümeleme analizi ise toplam 5 makalede verilerin analizinde kullanılan testler olarak karşımıza çıkmıştır. Nicel desenlerin 
analizinde kullanılan ancak parametrik testler için gerekli olan varsayımların sağlanamadığı durumlarda kullanılan testlerden Kruskal Wallis $\mathrm{H}$, Mann Whitney $\mathrm{U}$ ve Wilcoxon işaretli sıralar testleri ise 12 makalede kullanılmıştır. Yine parametrik olmayan testlerden kabul edilen ki kare testi de 20 makalede tercih edilmiştir. Nitel veri analizi yöntemlerinden doküman analizi 4 makalede, içerik analizi ise 273 makalede ön plana çıkmıştır. 5 makale ise diğer testlerle analiz edildi şeklinde sınıflandırılmıştir.

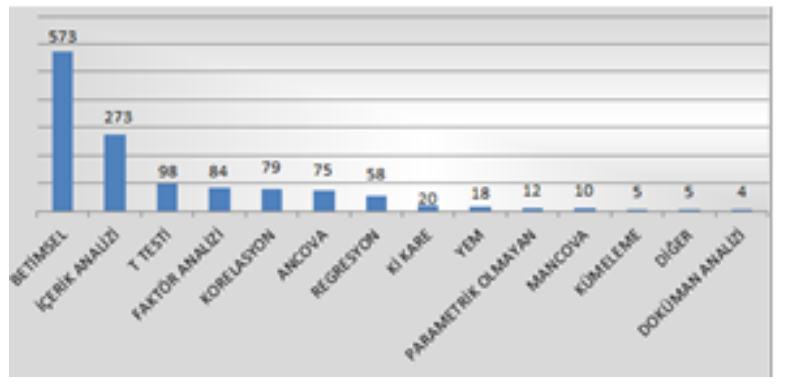

Şekil 11. Tercih edilen veri analizi tekniklerinin sayıları

\section{SONUÇ VE ÖNERİLER}

Bu çalışmada, uzaktan eğitim alanında önde gelen sekiz dergi (Internet \&Higher Education, American Journal of Distance Education, International Review of Research in Open and Distance Learning-IRRODL, Online Journal of Distance Learning Administration- OJDLA, Open Learning: The Journal of Open, Distance and e-Learning, Turkish Online Journal of Distance Education-TOJDE, European Journal of Open, Distance and E-Learning-EURODL, Distance Education) makale sayısı, kullanılan yöntemler, araştırma modelleri, araştırma türü, deseni, çalışma grubu, evren, örneklem, örneklem seçimi, örnekleme yöntemi, veri toplama araçları ve veri analiz yöntemi, açısından incelenmiştir.

Zawacki-Richter, Bäcker ve Vogt (2009)'un 2000-2008 yılları arasında yayınlanan makalesinde 2008 yılına doğru artış olduğunu ve en çok makalenin 2008 yılında yayınlandığını gösteren çalışmasını destekler nitelikteki araştırma bulguları bu artışın devam etmekte, 20092013 yılları arasinda 2010 yilı ve sonrasinda artış olduğu ve en çok makalenin 2013 yılında yayınlandığ1 görülmektedir. Makaleler incelendiğinde farklı disiplinlerde ve örneklem gruplarında çalışmalar yapıldı̆̆ı görülmektedir. $\mathrm{Bu}$ nedenle artışın sebebinin kurumların uzaktan eğitim alanına yönelik olumlu algıları olabilir. Ayrıca araştırmalardaki artışın uzaktan eğitim çalışmalarının öneminin her geçen gün artmasına bağlanabileceği düşünülmektedir.

Dergilere göre makale sayıları incelendiğinde, en çok makalenin TOJDE' de yayınlandığı, bunu IRRODL, Internet \&Higher Education ve ODJLA dergilerinin takip ettiği belirlenmiştir. TOJDE' de yayınlanan makale sayısının fazla olması, bu derginin Türkiye adresli olmasından kaynaklandığı düşünülmektedir. Diğer dergilerde yer alan makale sayısının az olması dergilerin yayın politikaları, dergilere gönderilen makalelerin kalitesi ve sayısı gibi etkenler olabilir.

İncelenen makalelerde ağırlıklı olarak nitel araştırma paradigmasının temel alındığı, araç geliştirme çalışmalarının ise çok düşük olduğu görülmektedir. Çalışmalarda nitel yöntem kullanımı yüksek olsa da, özellikle 2011 yılından sonra nitel çalışmalarda yüzde yirmi beş oranında azalma görülürken, nicel yöntem, araç geliştirme, literatür tarama ve karma yöntem kullanılan çalışmalarda ise artış görülmektedir. Zawacki-Richter, Bäcker ve Vogt (2009)' un yapmış oldukları çalışmada da \%29.1 oranında nicel yöntem kullanımı söz konusudur. Dolayısıyla iki çalışma sonuçları incelendiğinde 2000-2013 yılları arasında nicel yöntem araştırmalarına doğru bir yönelim olduğu söylenebilir. Dergilere göre kullanılan yöntemler ince- 
lendiğinde AJDE, EURODL, Internet \& Higher Education, OJDLA dergilerinde çoğunlukla nicel paradigma, TOJDE, Open Learning dergisinde literatür taraması, IRRODL, Distance Education dergisinde ise nitel paradigma çalışmalarına doğru yönelim olduğu görülmektedir. Bu bulgular göz önüne alınarak nitel yöntem araştırmalarındaki azalmanın nedeni incelenen sekiz dergiden dördünün nicel yöntem çalışmalarını tercih etmelerinden ya da nicel yöntemlerin çalışma sonuçlarını genelleme, geniş örneklemlere ulaşma, zaman ve maliyet bakımından sağladığı avantajlardan kaynaklanabilir.

Uzaktan eğitim dergilerindeki makalelerin desen tercihleri ele alındığında nicel paradigmada tarama, nitel paradigmada ise örnek olay desenlerinin açı ara ön plana çıtığ görülmüştür. Literatür incelendiğinde önceki çalışmaların da benzer sonuçları işaret ettiği görülmektedir (Lee ve ark., 2010).

Makaleler incelendiğinde temel alınan çalışma grubu, evren ve örneklem özellikle lisans düzeyinde öğrencilerle ve yüksek oranda katılımc1 sayısıyla ön plana çıkmaktadır. Bu bulgular, çalışmaların lisans düzeyinde öğrencilerle daha ağırlıklı olduğunu göstermektedir. Ancak bu bulgu Davies, Howell ve Petrie' nin (2010) çalışmalarındaki lisansüstü öğrencileriyle yapılan çalışmaların ağırlıklı olduğu bulgusu ile çelişmektedir. Araştırmada örneklem alınan çalışmalarda hangi örnekleme yönteminin tercih edildiği incelendiğinde ise amaçlı örnekleme yöntemi kullanıldığı belirlenmiştir. Bunun nedeni örneklemi derinlemesine araştırabilmek için örneklem grubunun küçük olması olabilir. $\mathrm{Bu}$ gibi durumlarda rasgele örneklem seçimi yerine, amaçlı örnekleme tercih edilir (Miles ve Huberman, 1994). Şimşek ve arkadaşları (2008), Akça-Üstündağ (2009) ile Alper ve Gülbahar (2009) da çalışmalarında en fazla tercih edilen örneklem seçim tekniklerinin kolay ulaşılabilir ve amaca uygun olduğunu belirtmişlerdir. $\mathrm{Bu}$ bilgiler göz önüne alınarak ulaşılan bu bulgunun, araştırmaciların örnekleme ulaşma kolaylıklarından ya da örneklem seçim yöntemleri- nin daha ekonomik olmasından kaynaklandığı söylenebilir.

Araştırma kapsamında incelenen makalelerde kullanılan veri toplama araçları incelendiğinde çalışmalarda sırasıyla anket, görüşme formu ya da kayıtları ile ölçek kullanıldığı görülmektedir. Bu bulgu Davies, Howell ve Petrie'nin (2010) bulguları ile tutarlıdır. Diğer veri toplama tekniklerine (görüşme, gözlem) göre anketin kullanılmasının sebebinin farklı bölgelerden çok daha büyük gruplara hızla uygulama olanağının olması ve maliyetinin daha düşük olması gibi avantajlarından kaynaklandığı düşünülmektedir.

Makalelerde kullanılan analiz teknikleri ele alındığında nicel ve nitel betimsel analizlerin yapıldığı görülmüştür. Nicel parametrik analiz tekniklerinden sırasıyla T-testi, faktör analizi, güvenirlik ve korelasyon analizinde kullanılan testler tercih edilmiştir. Bu bulgu Saba (2000), Berge ve Mrozowski (2001) bulguları ile tutarlıdır. Nicel desenlerin analizinde kullanılan ancak parametrik testler için gerekli olan varsayımların sağlanamadığı durumlarda kullanılan testlerden ki kare, Kruskal Wallis H, Mann Whitney $U$ ve Wilcoxon işaretli sıralar testleri kullanılmıştır. Nitel veri analizi yöntemlerinden ise içerik analizi kullanımı ön plana çıkmaktadır.

Özet olarak çalışmanın uzaktan eğitim dergilerinde yayınlanan makalelerin yöntemsel açıdan eğilimlerini belirlemeye yönelik yürütülen çalışmalarla karşılaştırıldığında incelenen makale sayısı ve araştırma soruları açısından daha kapsamlı olduğu belirtilebilir. Çalışmadan elde edilen sonuçların uzaktan eğitim alanında gelecek çalışmalara yön vermede belirleyici bir kaynak olarak kullanılabileceği düşünülmektedir. Buna karşın çalışma sonuçlarının 2009-2013 yılları arasında sekiz uzaktan eğitim dergisinde yayınlanan 1233 araştırmayla sınırlı olduğu unutulmamalıdır. Bu doğrultuda gelecek çalı̧̧malarda farklı tarihlerde, dergi sınırlaması yapılmadan makalelerin incelenmesi uzaktan eğitim araştırmalarının gelişimi ve eğilimleri 
yansitmada daha geniş bir tablo çizeceği düşünülebilir.

\section{Kaynakça}

Akça-Üstündağ, D. (2009). Türkiye'de Bilgisayar ve Öğretim Teknolojileri Alanında Yapılan Yüksek Lisans Tezlerinin İçerik ve Yöntem Açısından Değerlendirilmesi. Yayımlanmamış Lisans Tezi, Gazi Üniversitesi, Ankara.

Alper, A. ve Gülbahar, Y. (2009). Trends an Dissues in Educational Technologies: A Review of Recent Research in TOJET. The Turkish Online Journal of Educational Technology, 8 (2), 124-135.

Anglin, G. ve Morrison, G. (2000). An Analysis of Distance Education Research: Implications for the İnstructional Technologist. Quarterly Review of Distance Education, 1(3), 180194.

Berge, Z. ve Mrozowski, S. (2001). Review of Research in Distance Education. American Journal of Distance Education, 15(3), 5-19.

Bernard, R., Abrami, P., Lou, Y., ve Borokhovski, E. (2004). A Methodological Morass? How We Can İmprove Quantitative Research in Distance Education. Distance Education, 25(2), 175-198.

Bozkurt, A., Akgün-Ozbek, E., Yılmazel, S., Erdoğdu, E., Uçar, H., Güler, E., ve Aydın, C. H. (2015). Trends in Distance Education Research: A Content Analysis of Journals 2009-2013. The International Review of Research in Open and Distributed Learning, 16(1).

Chung, S. H. ve Khor, E. T. (2015). Development of Interactive Mobile-Learning Application in Distance Educationvia Learning Objects Approach. In New Trends in Intelligent Information and Database Systems (pp. 373-380). Springer International Publishing.

Davies, R. S. Howell, S. L., ve Petrie, J. A. (2010). A Review of Trends in Distance Education Scholarship at Research Universities in North America, 1998-2007. International Review of Research in Open and Distance Learning, 11(3), 42-56.

Diaz, D. P. (2000). Carving a New Path for Distance Education Research. The Technology Source. http://horizon.unc.edu/TS/default.asp?show articleandid 68 adresinden 8 Eylül 2015 tarihinde indirilmiştir.

Hauser, L. (2013). Qualitative Research in Distance Education: An Analysis of Journal Literature 20052012. American Journal of Distance Education, 27(3), 155-164.

Holmberg, B. (1985). Status and Trends of Distance Education. Lund: Lector Publishing.

Horzum, M. B., Özkaya, M., Demirci, M., ve Alpaslan, M. (2013). Türkçe Uzaktan Eğitim Araştırmalarının İncelenmesi. İnönü Üniversitesi Eğitim Fakültesi, 142, 1-12.

Hwang, G.,Vu, P. ve Chen, C.(2012). An Online Game Approach for Improving Students' Learning Performance in Web-Based Problem-Solving Activities. Computers ve Education, 59, 1246- 1256.

Kaya, Z. (2002), Uzaktan Eğitim, Ankara: Pegem A Yayıncilı. http://www.jret.org/FileUpload/ds217232/File/uzaktanegitim.pdf adresinden_8 Eylül 2015 tarihinde indirilmiştir.

Koble, M. A. ve Bunker, E. L. (1997). Trends in Research and Practice: An Examination of The American Journal of Distance Education 1987-1995. American Journal of Distance Education, 11(2), 19-38.

Koper, R. (2015). How Do Students Want to Learn in Online Distance Education? Profiling Student Preferences. The International Review of Research in Open and Distributed Learning, 16(1). 
Lee, Y., Driscoll, M. P. ve Nelson, D. W. (2004). The Past, Present, and Future of Research in Distance Education: Results of a Content Analysis. The American Journal of Distance Education, 18(4), 225241.

Miles, B. M. ve Huberman A. M. (1994). Qualitative Data Analysis: An Expanded Source Book. 2nd ed. California, USA: Sage Publications, p.27.

Mishra, S. (1997). A Critical Analysis of Periodical Literature in Distance Education. Indian Journal of Open Learning, 6(1\&2), 39-54.

Moore, M. And Thompson, M. M. (1997). The Effects of Distance Learning, New York: American Center for the Study of Distance Education.

Panda, S. (1992). Distance Educational Research in India: Stock-Taking, Concerns and Prospects. Distance Education, 13(2), 309-326.

Perraton, H. (2000). Rethinking the Research Agenda. International Review of Research in Open and Distance Learning, 1(1). Retrieved July 18, 2001, from http://www.irrodl.org/v1.1html adresinden 08 Eylül 2015 tarihinde indirilmiştir.

Phipps, R. ve Merisotis, J. (1999). What's the Difference? A Review of Contemporary Research on the Effectiveness of Distance Learning in Higher Education. Washington, DC: The Institute for Higher Education Policy.

Rourke, L. ve Szabo, M. (2002). A Content Analysis of the Journal of Distance Education 19862001. International Journal of E-Learning \& Distance Education, 17(1), 63-74.

Saba, F. (2000). Research in Distance Education: A status report. International Review of Research in Open and Distance Education, 1(1), 19.

Scriven, B. (1991). Ten Years of 'Distance Education'. Distance Education, 12(1), 137-153.

Sherry, L. 1996. Issues in Distance Learning. International Journal of Educational Telecommunications1 (4): 337-65. http://ldt.stanford.edu/ leemba/ldt/resources/issues in distance learning.htm adresinden 08 Eylül 2015 tarihinde indirilmiştir.

Simonson, M., Smaldino, S., Albright, M. ve Zvacek, S. (2008). Teaching and Learning at a Distance Foundations of Distance Education (4th ed.). http://learning.fon.edu.mk/knigi/teachinganlearningatadistance4.pdf2 Eylül 2015 tarihinde indirilmiştir.

Yıldırım, A. ve Şimşek, H. (2008). Sosyal Bilimlerde Nitel Araştırma Yöntemleri (6. Baskı) Ankara: Seçkin Yayıncilik

Zawacki-Richter, O. (2009). Researchareas in Distance Education: A Delphi Study. The International Review of Research in Open and Distributed Learning,10(3).

Zawacki-Richter, O. ve vonPrümmer, C. (2010). Gender and Collaboration Patterns in Distance Education Research. Open Learning, 25(2), 95-114.

Zawacki-Richter, O., Bäcker, E. M. ve Vogt, S. (2009). Review of Distance Education Research (2000 to 2008): Analysis of Research Areas, Methods, and Authorship Patterns. International Review of Research in Open \& Distance Learning, 10(6). 


\section{Extended Summary}

When the studies about distance education is analyzed, it is seen that in our country, a limited number of studies are conducted especially about the methods used; much more and more improved studies are conducted in abroad. These articles that are conducted in abroad and focus on distance education research show that most of the studies are descriptive and the non-descriptive ones are methodologically problematic.

The purpose of the study is to examine articles, published in 8 journals in the last 5 years, about distance education with respect to the method. In order to achieve the objectives of the research, the following research questions were aimed to be answered: "What are the research methods used in distance education research ?, What are the models used in distance education research? Who is the sample group in the research? How many people were at the study? What is used as a data collection tool? What are the statistics used in research?

This study was conducted with qualitative document review method. A total of 1233 articles, which was published in 8 journals in the last 5 years about distance education, were analyzed within the scope of this research. Articles examined in the study were analyzed in terms of type of research, design, sample selection, sampling methods, measurement tools and analysis methods.

The Examination of Methodological Trends in Distance Education Articles Form, which was developed by researchers, was used as a data collection tool. This form included items like journal name, year of publication, method, research design, population and sampling, data collection tools, collection and analysis of data.

Articles in the current study were collected from the websites of the respective journals as for year, number and volume by researchers. After data collection process, articles were classified and 10 articles were selected reflecting the items on the form. Then the form was filled by all researchers. Later, all articles were transferred independently to the form and it was classified by expert opinion in the ucertain situations. The data were analyzed by percentage and descriptive statistical methods. According to some data, comparative percentage and frequency.

When the dispersion of the articles with respect to the years are examined, 315 articles in 2013, more than the other years, are seen. When the articles are analyzed, it seen that studies were conducted in different disciplines and sample. Therefore, it can be said that the reason of the increase might be the companies' positive perceptions towards distance education.

When the number of articles with respect to journals were analyzed, it was stated that most of the articles were published by TOJDE and IRRPDL, Internet \& Higher Education and ODJLA followed it. The reason that the articles published in TOJDE outnumbered others might be that it originated from Turkey. The reason for the limited number of articles in other journals might be factors such as the editorial policy of journals, the quantity of the articles submitted to the journals and quality

Examined articles Show that regarding the research methods, quantitative analysis was generally used in these studies. Furthermore the development of materials is seen to be very limited. Even though the high use of qualitative methods in these studies, five to twenty percent reduction was observed in the qualitative study especially after 2011. With respect to using quantitative methods, studies conducted with material development, literature review and mixed methods increased. 
When articles in distance education journals were examined wth respect to design preferences, it was seen that survey design in quantitative paradigm and case design in quality paradigm were used. When the studies were analyzed it was highlighted that main study group, sample and population were especially undergraduate students with high number of participants. These findings suggest that studies were conducted more often with undergraduate students.

When the preferred sampling method of the studies were analyzed, it was stated that purposeful sampling was used. The probable reason might be that samples of groups are small to investigate the smple group deeply. Respectively questionnaire, interview form or interview records and scale were used as a data collection tool

Given the analysis techniques used in articles, it was seen that quantitative and qualitative descriptive analysis were done. Parametric analysis of quantitative techniques, respectively, t-test, factor analysis, reliability and tests which used in the correlation analysis were preferred. When the assumptions can not be achieved, Chi-square, Kruskal-Wallis H, Mann Whitney U test and the Wilcoxon signed rank test were used of. Of qualitative data analysis methods, the content analysis was widely used.

In summary, it can be asserted that this study is more comprehensive with respect to the number of articles and research questions compared to other studies, conducted to determine the inclination with respect to method, published in distance education journals. It is thought that the results obtained from this study could be used as a diagnostic resource to guide future studies in the field of distance education. However, it should be noted that results of the study are limited to years between 2009-2013 and 1335 articles which were published in eight distance education journals. The results coming out of this study will be helpful in directing the future studies. In this direction, it can be thought that with the article investigation, without article restriction and with different date range, a wider trend could be drawn in reflecting distance education development and inclination. 